\title{
A critical review of the recent literature and selected therapy guidelines since 2006 on the use of lamotrigine in bipolar disorder
}

This article was published in the following Dove Press journal:

Neuropsychiatric Disease and Treatment

17 January 2013

Number of times this article has been viewed

\author{
Anja Tränkner \\ Christian Sander \\ Peter Schönknecht \\ Department of Psychiatry \\ and Psychotherapy, University \\ Hospital Leipzig, Leipzig, Germany
}

Correspondence: Peter Schönknecht Department of Psychiatry and Psychotherapy, University Hospital Leipzig, Leipzig, Germany, Semmelweisstr, 10, DE-04I 03 Leipzig, Germany Tel +49 34I 9724506

Email peter.schoenknecht@medizin. uni-leipzig.de

\begin{abstract}
The anticonvulsant drug lamotrigine (LTG), a sodium channel blocker and inhibitor of glutamate release, has been found to have antidepressant effects in the treatment of bipolar disorder. It is recommended by certain therapy guidelines as a first-line agent for acute and maintenance therapy in bipolar depression, but there have been only some promising results of placebo-controlled trials on its acute antidepressant effects, and the recommendation in therapy guidelines has been reconsidered. On the contrary, positive results for maintenance therapy could be confirmed, and LTG is still a well-tolerated option, especially in patients with predominant depressive episodes. Antimanic effects are not shown in the literature, and its use is not advised in any guidelines that were examined. In conclusion, the findings of the present review article on treatment guidelines for bipolar disorder question the role of LTG in acute depressive states, and critically discusses its use, particularly in acute depressive states.
\end{abstract}

Keywords: lamotrigine, bipolar disorder, bipolar depression

\section{Introduction}

Bipolar disorder (BD) is a chronic mood disorder with episodes of elevated or irritable mood, referred to as mania (or a milder form, hypomania), and episodes of depressive symptoms. The aggregate lifetime prevalence for bipolar 1 disorder (BD1) is $0.6 \%$, for bipolar 2 disorder (BD2) is $0.4 \%$, and for subthreshold BD is $1.4 \%{ }^{1}$ Treatment of different affective conditions is challenging; distinct treatment strategies, not only for acute episodes, but also for prevention of relapse of either depression or mania are essential. Different guidelines dealing with this problem are published, and because of newly approved drugs and an increase in studies that are being conducted, publications need to be edited permanently. We would like to discuss the changing role of lamotrigine (LTG) in selected treatment guidelines based on findings in publications dealing with LTG actions in the acute treatment and prevention of BD, mainly by including publications cited by the named guidelines (see Table 1). When the first guidelines were published pertaining to LTG as a treatment option for BD, only data with positive and supportive results were available, and it was strongly recommended as a first-line agent. When meta-analyses including more modest or even negative results were published, the role of LTG was reconsidered.

LTG, an antiepileptic drug that has been approved by US Food and Drug Administration (FDA) since 1993, acts through the inhibition of the sodium-dependent release of glutamate by blocking voltage-sensitive sodium-channels. ${ }^{2}$ Additionally, LTG diminishes neuronal transmission through blocking $\mathrm{N}$-type calcium-channels 


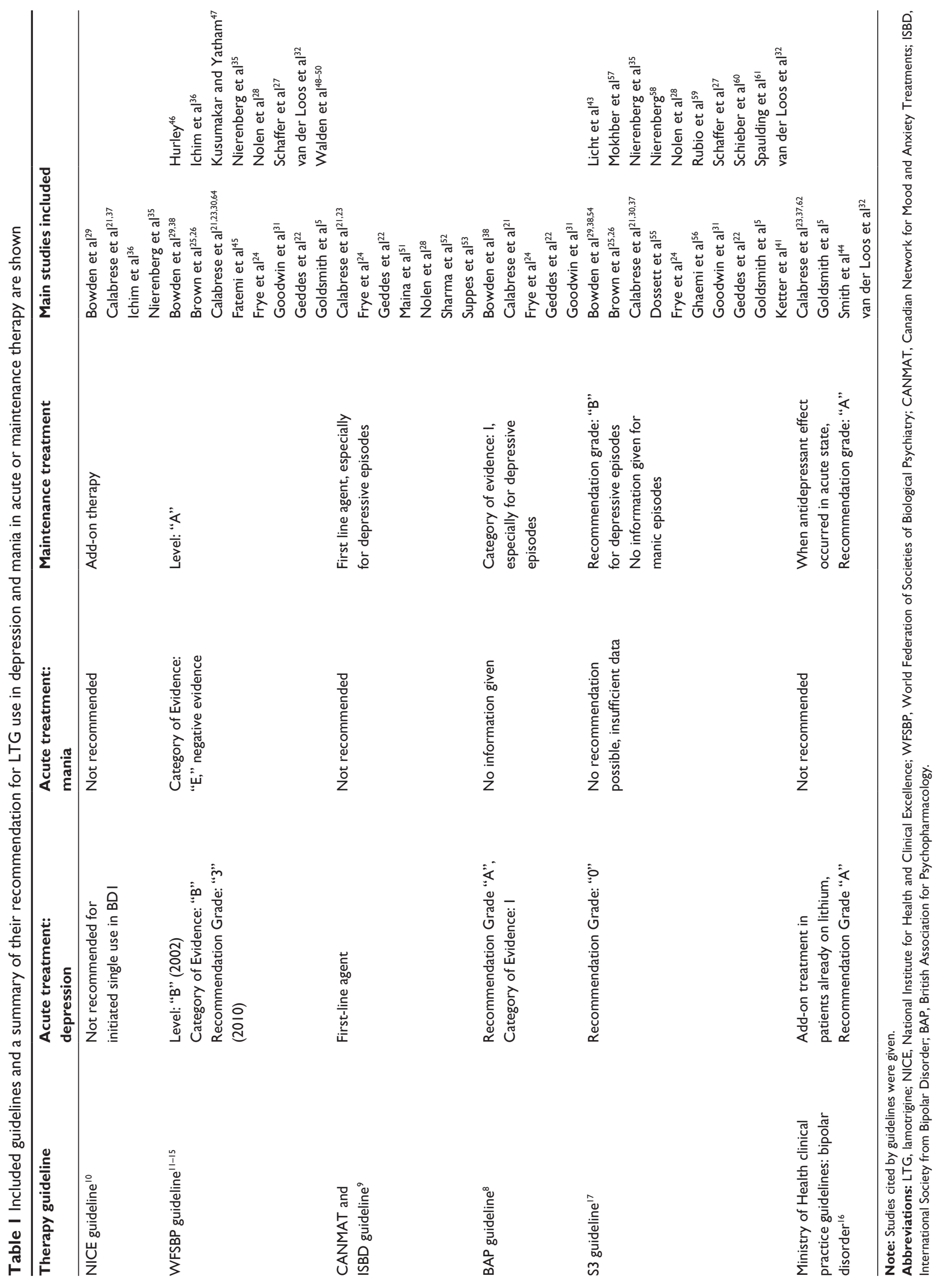


and the potassium outward current. ${ }^{3}$ In mice treated with LTG $\left(32 \mathrm{mg} / \mathrm{kg}\right.$ ), Prica et al ${ }^{4}$ showed a significant decrease in immobility time in a forced swimming test as an animal model for depression. By adding the sodium-channel activator, veratrine, this effect was reversed. This could not be repeated using different antidepressants, so the authors presumed that sodium channel blocking is a potential antidepressant mechanism of LTG.

Clinically, LTG is generally well tolerated, and the most common adverse events (AE) include headache, nausea, and rash. ${ }^{5,6}$ In trials comparing LTG with placebo (PLC), AE and rates of withdrawal due to $\mathrm{AE}$ did not differ significantly between groups. Seo et $\mathrm{al}^{6}$ found no association between the rates of AE and LTG dose when comparing doses of $50 \mathrm{mg}$ and $200 \mathrm{mg}$ LTG per day. In Stevens-Johnson syndrome, a hypersensitive reaction of the skin tissue and blood vessels due to drug exposure and in toxic epidermal necrolysis (also called Lyell's disease, which is a more severe skin reaction as seen in Stevens-Johnson syndrome), the incidence in patients treated with LTG is approximately $0.13 \%$ for monotherapy and $0.08 \%$ in adults receiving LTG as adjunctive therapy. ${ }^{6} \mathrm{To}$ avoid this condition, it is recommended that LTG be tapered over a 6-week period. ${ }^{7}$

\section{Methods}

We performed a search for the latest updates of treatment guidelines for BD among the following: the British Association for Psychopharmacology guidelines $2009 ;{ }^{8}$ the Canadian Network for Mood and Anxiety Treatments and International Society for Bipolar Disorder guidelines 2009; ${ }^{9}$ the National Institute for Health and Clinical Excellence (NICE) guidelines 2006; ${ }^{10}$ the World Federation of Societies of Biological Psychiatry guidelines; ${ }^{11-15}$ the Ministry of Health Clinical Practice Guideline: Bipolar Disorder, ${ }^{16}$ and the $\mathrm{S} 3$ guidelines on diagnostics and therapy of $\mathrm{BD} .{ }^{17}$ The search was conducted using the electronic databases MEDLINE and PubMed, and the Cochrane Library. We obtained relevant articles on LTG from citation indices of the named guidelines (for a detailed presentation, see Table 1). We then performed a search for English language articles in the same electronic databases using the keywords "lamotrigine" and "bipolar depression," as well as "lamotrigine" and "mania." Obtained articles were selected if they were randomized controlled trials (RCT) with PLC, Phase III studies and meta-analyses including RCT; or Phase III studies or meta-analyses including RCT; or Phase III studies (Tables 2 and 3). The retrieved articles were compared with previous findings from the reference lists and three more reviews were added, ${ }^{18-20}$ in addition to the single studies named in the guidelines (Table 2).

\section{Results LTG and treatment of BD}

The first RCT comparing LTG over PLC in bipolar 1 depression was conducted in 1999 by Calabrese et al. ${ }^{21}$ A total of 195 patients received either LTG $50 \mathrm{mg}$ /day, LTG $200 \mathrm{mg} /$ day, or PLC as monotherapy. For the primary outcome measure, which was defined by a difference of 5.0 points in the 17-item Hamilton Rating Scale for Depression (HAM-D), the study failed. Nevertheless, the authors found a response within the first 3 weeks, and statistical significance using last observation carried forward (LOCF) could be shown in week 5 for patients taking $200 \mathrm{mg}$ of LTG compared to the PLC group in the Montgomery-Åsberg Depression Rating Scale (MADRS), the Clinical Global Impressions scale for Improvement, and the Clinical Global Impressions scale of Severity (CGI-S). In 2009, Geddes et al conducted a metaanalysis of five RCTs published by GlaxoSmithKline (GSK) including Phase III studies and the RCT by Calabrese et al, ${ }^{8}$ and found a small but consistently positive effect of LTG monotherapy compared to PLC when the results were pooled. ${ }^{22}$

When examined in detail, four of five studies were underpowered and failed to show a superiority of LTG over PLC. The relative risks of response ( $>50 \%$ reduction in the baseline scores of HAM-D and MADRS) and remission ( $<8$ on HAM-D and $<12$ on MADRS) were calculated. The pooled risk ratio (RR) for a reduction of $>50 \%$ in HAM-D was 1.27 (95\% CI: $1.09-1.47, \mathrm{df}=4, P=0.772$ ) and 1.22 in MADRS (95\% CI: $1.06-1.41, \mathrm{df}=4, P=0.538$ ). When the authors distinguished between mild (HAM-D $<24)$ and severe depression (HAM-D $\geq 24$ ), a significant therapeutic effect of LTG compared to PLC (RR $=1.47,95 \%$ CI 1.16-1.87, $P=0.001)$ could be found only in patients in a severe state of depression (regression coefficient $=0.30,95 \%$ CI: $0.14-0.60$, $P=0.04)$. There was no significant difference between BP 1 and BP 2 patients (regression coefficient $=-0.06,95 \%$ CI: -0.35 to $0.24, P=0.705$ ).

In 2008, Calabrese et al ${ }^{23}$ published a similar overview of the results of these four Phase III studies by GSK, as well as the Lamictal 602 study ${ }^{21}$ and the authors found that only in the Lamictal 602 study was there a significant reduction in the HAM-D score in the LTG group compared to the PLC group $(P<0.05)$. This result could not be repeated in the other four trials, and LTG and PLC did not statistically differ in terms of changes in the 17-item or 31-item HAM-D scores. 


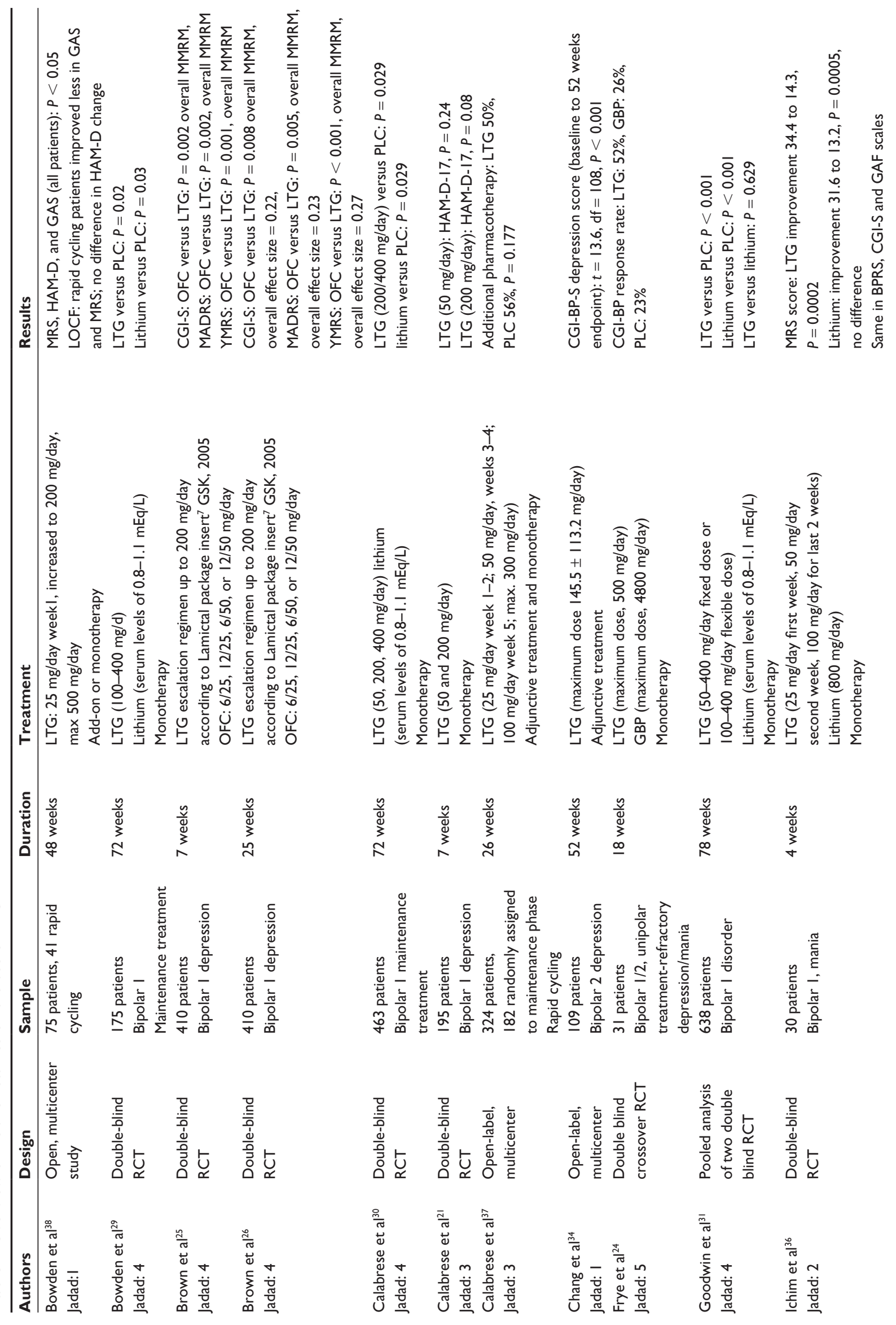



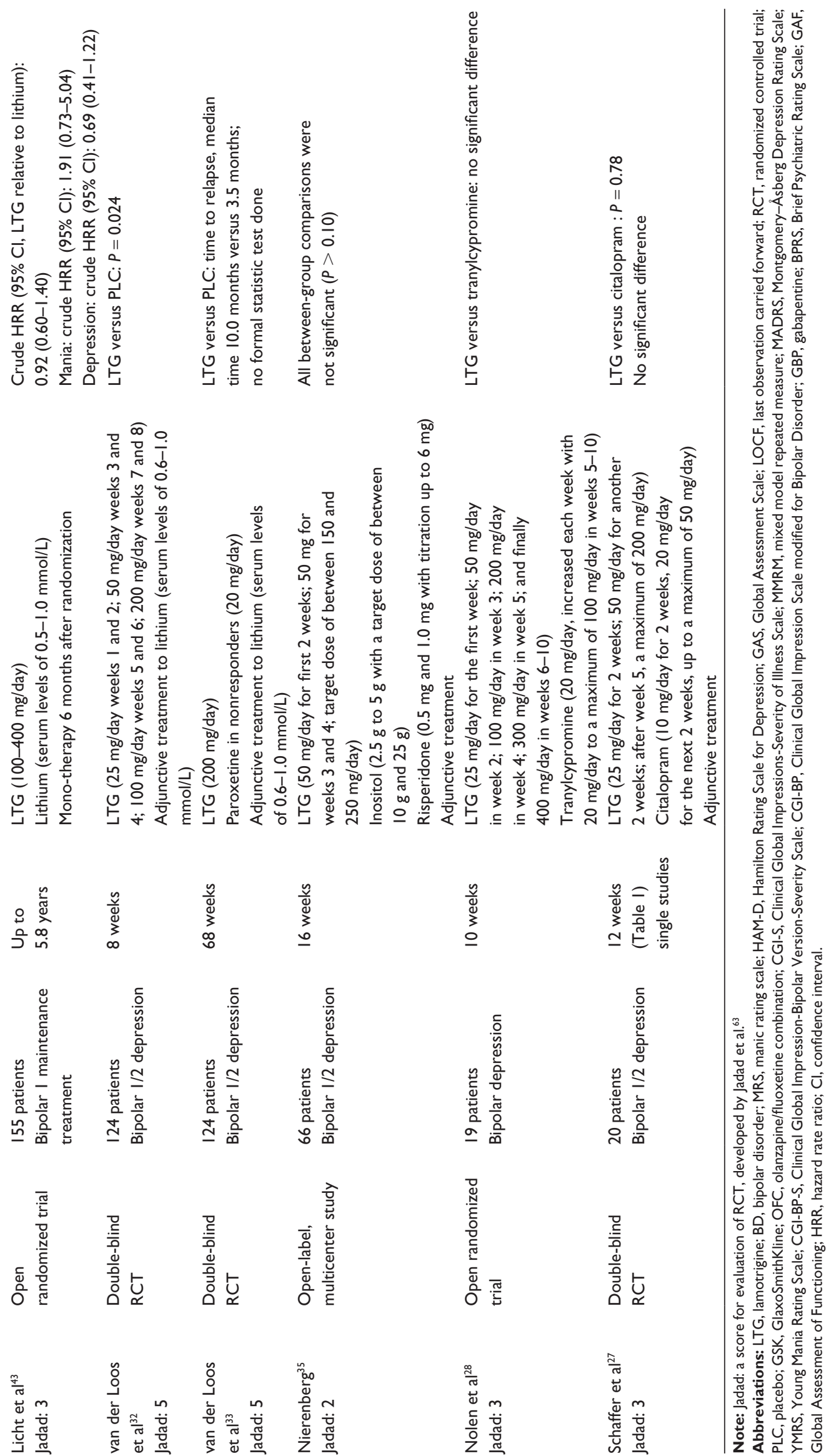

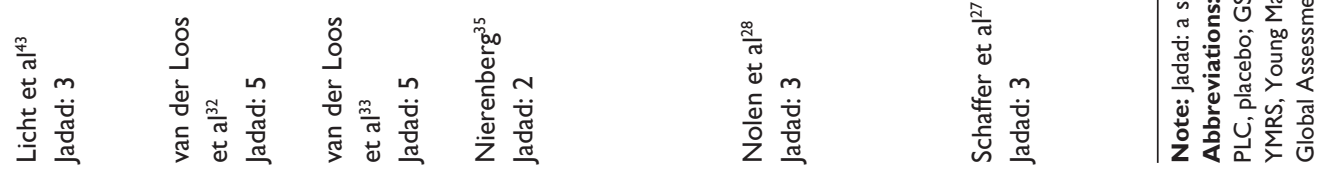


Table 3 Meta-analyses and review articles used in this publication and listing of included trials

\begin{tabular}{|c|c|c|}
\hline Authors & Design & Studies included \\
\hline \multirow[t]{11}{*}{ Amann et al $^{18}$} & Meta-analysis & SCAA2008 \\
\hline & & SCAA2009 \\
\hline & & SCAI00223 \\
\hline & & SCA30924 \\
\hline & & SCA409I0 \\
\hline & & SCAA20I0 \\
\hline & & SCAB2005 \\
\hline & & Calabrese et $\mathrm{al}^{21,30,37}$ \\
\hline & & Bowden et $\mathrm{al}^{29}$ \\
\hline & & Brown et $\mathrm{al}^{25}$ \\
\hline & & van der Loos et $\mathrm{al}^{32}$ \\
\hline \multirow[t]{5}{*}{ Calabrese et $\mathrm{al}^{23}$} & Report of five RCT & SCAI00223 \\
\hline & & SCA30924 \\
\hline & & SCA40910 \\
\hline & & SCAA2010 \\
\hline & & SCAB200I \\
\hline \multirow[t]{3}{*}{ Cipriani et al ${ }^{19}$} & Meta-analysis & SCAA2008 \\
\hline & & SCAA2009 \\
\hline & & Ichim et $\mathrm{al}^{36}$ \\
\hline \multirow[t]{7}{*}{ Geddes et $\mathrm{al}^{22}$} & Meta-analysis and & SCAI00223 \\
\hline & Meta-regression & SCA30924 \\
\hline & of five RCT & SCA409I0 \\
\hline & & SCAA20I0 \\
\hline & & SCAB200I \\
\hline & & Raw data sets \\
\hline & & conducted by GSK \\
\hline \multirow[t]{4}{*}{ Goldsmith et $\mathrm{al}^{5}$} & Review & Calabrese et $\mathrm{al}^{21,30,37,64}$ \\
\hline & & Bowden et $\mathrm{al}^{29}$ \\
\hline & & Frye et $\mathrm{al}^{24}$ \\
\hline & & Obrocea et $\mathrm{al}^{65}$ \\
\hline \multirow[t]{4}{*}{ Yildiz et $\mathrm{al}^{20}$} & Meta-analysis of RCT & GW609 (GSK) \\
\hline & & GW6I0 (GSK) \\
\hline & & Ichim et $\mathrm{al}^{36}$ \\
\hline & & Goldsmith et $\mathrm{al}^{5}$ \\
\hline
\end{tabular}

Notes: SCAA2008, SCAA2009, SCA100223, SCA30924, SCA409I0, SCAA20I0, SCAB2005, SCAB200I, GW609, and GW6I0 are raw data sets conducted by GSK.

Abbreviations: RCT, randomized controlled trials; GSK, GlaxoSmithKline.

In another RCT conducted with either unipolar or bipolar patients, LTG monotherapy was compared to gabapentin (GBP) monotherapy or PLC over the course of 6 weeks, with two subsequent crossover trials. ${ }^{24}$ Overall response rates as a primary outcome, with response defined as "much improved" or "very much improved" in the CGI-Bipolar scale, were LTG 52\%, GBP 26\%, and PLC 23\% (Cochrane's $\mathrm{Q}[\mathrm{n}=31, \mathrm{df}=2]=6.952, P=0.031)$. A positive trend for the superiority of LTG monotherapy in the treatment of patients with refractory mood disorder could be shown (post hoc Q differences: $\mathrm{LTG}$ versus GBP, Qdiff $=5.33, P=0.011$; $\mathrm{LTG}$ versus $\mathrm{PLC}, \mathrm{Qdiff}=4.76, P=0.022$; and GBP versus $\mathrm{PLC}$, Qdiff $=0.08, P=0.700){ }^{24}$
In 2006, Brown et $\mathrm{al}^{25}$ compared LTG with the combination of olanzapine/fluoxetine (OFC) in the acute treatment of bipolar 1 depression. Primary outcome measure was defined as change in the CGI-S score from baseline. A significantly greater improvement in the OFC group compared to the LTG group could be shown $(P=0.002$, overall mixed model repeated measures [MMRM] ). Also in MADRS $(P=0.002)$ and Young Mania Rating Scale scores, a greater improvement among the OFC group was found $(P=0.001)$. The response rates of both treatment groups did not differ significantly (response defined as $\geq 50 \%$ reduction in MADRS total score, OFC: $68.8 \%$ versus LTG: $59.7 \%, P=0.073$ ). These results could be confirmed in the follow-up trial, which was conducted over 25 weeks. Patients receiving OFC showed greater improvements in week 25 in CGI-S ( $P=0008$ overall MMRM, overall effect size $=0.22$ ) and MADRS total scores $(P=0.005$ overall MMRM, overall effect size $=0.23)$. Time to response was shorter for the OFC group than for the LTG group, and response and remission rates were similar in both treatment groups. ${ }^{26}$

LTG was compared to citalopram in a RCT by Schaffer et al in $2006 .{ }^{27}$ The authors examined patients with $\mathrm{BD} 1$ or $\mathrm{BD} 2$ disorder who were in a current depressive episode, and in this small sample size $(n=20)$, both treatment groups had a significant reduction in MADRS score from baseline (LTG $\Delta-13.3, \mathrm{SD}=8.0 ; P=0.001$; citalopram $\Delta-14.2, \mathrm{SD}=10.2, P=0.002)$, but no differences between these groups could be shown ( $\mathrm{F}=0.55, \mathrm{df}=7, P=0.78)$. Therefore, the obtained responses, remission rates, and levels of reduction did not differ between the two groups.

Nolen et $\mathrm{al}^{28}$ also compared LTG with an antidepressant. Patients with refractory bipolar depression who were already on mood stabilizers were treated either with supplementary LTG or tranylcypromine. This trial was underpowered because of a small sample size and could not show statistically significant differences in terms of changes in depressive symptoms between the two agents, but the authors found a positive trend for tranylcypromine. Both drugs exhibited positive trends, but evidence for an acute antidepressant effect of LTG is sparse.

The role of LTG in the maintenance treatment and prevention of depressive episodes is more convincing. Bowden et $\mathrm{al}^{29}$ and Calabrese et al ${ }^{30}$ published the results of two randomized, PLC-controlled trials in which patients with BD1 who had recently undergone either manic/hypomanic or depressive episode were treated with LTG, lithium, or PLC. Calabrese et $\mathrm{al}^{30}$ found that both agents were significantly 
superior to PLC for the time to intervention for any mood episode (LTG versus PLC: $P=0.029$; lithium versus PLC: $P=0.029)$; however, both agents did not differ on this measure $(P=0.915)$. The authors found evidence that LTG is superior to PLC for prolonging time to relapse for depressive episodes $(P=0.047)$; lithium showed an effect on prolonging time for manic episodes $(P=0.026)$. Similar results were published by Bowden et al, ${ }^{29}$ and time for intervention for any mood episode was extended with both agents (LTG versus PLC: $P=0.02$; lithium versus PLC: $P=0.003$ ).

These results were confirmed in a pooled analysis of these two RCT. It was concluded that lithium and LTG prevent the relapse of any mood episode, which is superior to PLC (LTG versus PLC: $P<0.001$; lithium versus PLC: $P<0.001$ ), and that LTG showed greater effectiveness in prolonging time to intervention for depressive episodes compared to lithium (LTG versus PLC: $P=0.009$; lithium versus PLC: $P=0.120){ }^{31}$

In the trial of van der Loos et al, ${ }^{32}$ LTG was used as an add-on treatment compared to PLC in patients with bipolar 1 or 2 depression already on lithium monotherapy. First, they analyzed acute treatment effects within the first 8 weeks and there was a significant reduction in the MADRS total score in the LTG group compared to the PLC group (LTG -15.38 versus PLC $-11.03, P=0.024$, primary outcome). Response, which was defined as a reduction $\geq 50 \%$ in the MADRS total score, was also significantly distinct between the two groups $(P=0.03) .{ }^{32}$ When analyzing the follow-up data after 68 weeks, positive effects of LTG add-on treatment could be confirmed. ${ }^{33}$ The percentage of responders and time to relapse after response was higher in the LTG algorithm group (median time LTG group 10.0 months [95\% CI: 1.1-18.8] versus PLC group, 3.5 months [95\% CI: 0.7-7.0]). ${ }^{33}$

Chang et $\mathrm{al}^{34}$ conducted a prospective study dealing mainly with the long-term effects of adjunctive use of LTG over a 52-week period in BD2 patients with therapy refractory depression, treated previously with different mood stabilizers, atypical antipsychotics, and antidepressants. The effect size for changes in the CGI-Bipolar Version-Severity for depression was large (Cohen's $d>0.8$ ), and the reduction in the CGI-Bipolar Version-Severity scores from baseline to endpoint was significant ( $t=13.6, \mathrm{df}=108, P<0.001)$. Use of LTG in treatment-resistant bipolar depression was also examined by Nierenberg et al. ${ }^{35}$ LTG as an add-on treatment showed no difference compared to inositol or risperidone in the primary outcome measure, "rate of recovery;" however, the rate of recovery for LTG was $23 \%$, in contrast to $17.4 \%$ and $6.4 \%$ for inositol or risperidone, respectively, and a modest positive trend for LTG was revealed, supporting the findings from previous cited studies. . $1,22,24,27,30,32,33^{-33}$

\section{LTG and treatment of mania/mixed states}

Reliable evidence was not found for LTG for either acute or maintenance treatment of mania. All of the guidelines mentioned in this article do not recommend LTG as an option for therapy. ${ }^{9-12,15-17}$ Two recent meta-analyses compared different drugs approved for acute mania treatment. Yildiz et $\mathrm{al}^{20}$ could not show significant antimanic effects of LTG after meta-analytic calculation (Hedges' $g=-0.02$; $95 \% \mathrm{CI}-0.43$ to $0.39, P=0.927)$. They included the trial by Ichim et $\mathrm{al},{ }^{36}$ and one review of two trials conducted by GSK (GW609, GW610). In addition, Cipriani et al ${ }^{19}$ recently published one meta-analysis of antimanic drugs, including three RCTs dealing with LTG in antimanic therapy, two protocols published by GSK (SCAA2008, SCAA2009), and the trial of Ichim et al. ${ }^{36}$ The authors concluded that there is less efficacy of LTG in the acute treatment of mania compared to haloperidol, and this treatment is not superior to PLC (standardized mean difference [SDM] [95\% CI]: LTG versus haloperidol: -0.48 [ -0.77 to -0.19$]$, LTG versus PLC: 0.01 [ -0.21 to 0.22$]$ ). When compared to lithium, the authors found a greater effectiveness of LTG (SDM [95\% CI] LTG versus lithium: 0.21 [-0.02 to 0.50$]) .{ }^{19}$ Ichim et $\mathrm{al}^{36}$ found, in their RCT, significant effectiveness of LTG in treating mania, compared with lithium. But both drugs did not differ in terms of response rates across the different psychopathological rating scales (manic rating scale [MRS] score difference from baseline to week 4: LTG group improved from 34.4 to $14.3[P=0.002]$, lithium group improved from 31.6 to 13.2 $[P=0.005]$; CGI scale difference from baseline to week 4 : LTG group improved from 4.93 to 2.77 [ $P=0.002]$, lithium group improved from 4.67 to $2.83[P=0.005])$. Some limits of this publication include the absence of a PLC control group, the small number of included patients $(\mathrm{n}=30)$, and a low mean plasma level for lithium $(0.743 \mathrm{mmol} / \mathrm{L})$. There is also less evidence for the efficacy of LTG in maintenance treatment and prevention of manic episodes. Both Calabrese et $\mathrm{al}^{30}$ and Bowden et $\mathrm{al}^{29}$ showed that LTG is not superior to PLC in preventing manic relapse over an 18-month period (LTG versus PLC, $P=0.28$ ).

Another meta-analysis dealing with LTG actions in the treatment of BD was published by Amann et al, ${ }^{18}$ who asserted that LTG is inferior to lithium in preventing or improving manic symptoms or episodes. Amann et $\mathrm{al}^{18}$ analyzed the 
results of the previous studies by Calabrese et $\mathrm{al}^{30}$ and Bowden et $\mathrm{al}^{29}$ and they also included the RCT by GSK (study protocols SCAA2008 and SCAA2009). In the first of these two trials, both LTG and lithium showed no difference in terms of change in MRS score from baseline to day 22 compared to PLC. In the second study, lithium met the primary endpoint criteria. LTG was not superior to PLC in terms of changes in MRS score in manic patients.

In 2000, Calabrese et $\mathrm{al}^{37}$ published a double-blind, PLCcontrolled study including 324 patients meeting the criteria for rapid cycling $\mathrm{BD}$, and patients received LTG first as an add-on therapy or as a monotherapy in a randomized phase. For the primary endpoint, this study did not show a significant difference in the time to additional pharmacotherapy (median survival time for LTG: 18 weeks; PLC: 12 weeks; $P=0.177$ ). One year earlier, Bowden et $\mathrm{al}^{38}$ had shown that, in 75 patients with BD, whether rapid cycling or not, there was a significant change in MRS or HAM-D scores from baseline across both groups (rapid-cycling and non-rapid-cycling patients, $P<0.05)$. However, rapid-cycling patients showed less improvement in MRS scores after the last observation carried forward in week 48 than did non-rapid-cycling patients. This was not found in initially depressed patients when the HAM-D score differences were compared.

\section{Discussion}

In this review, we discussed the role of LTG in recent guidelines based on findings from literature indices and databases. First, studies dealing with therapeutic options of LTG published promising results. ${ }^{21,24}$ These two RCT provided reasoning to recommend LTG as a first-line agent in the acute treatment and prophylaxis of bipolar depression in accordance with the guidelines from the British Association of Psychopharmacology in 2009; the meta-analysis by Geddes et $\mathrm{al}^{22}$ supported this decision (Table 3 ). The Canadian Network for Mood and Anxiety Treatments and the International Society for Bipolar Disorder, in 2009, also proposed LTG for the treatment and prevention of acute depressive episodes. ${ }^{9}$ In contrast, NICE Guidelines $(2006)^{10}$ do not advise using LTG as first-line monotherapy in acute depression, and suggest LTG as a second mood stabilizer when the combination of an antidepressant and mood stabilizer has failed. For BD2 patients and patients with chronic or recurrent depressive episodes, LTG as monotherapy is advised. ${ }^{10}$ Grunze et al ${ }^{11-15}$ discussed the role of LTG in their recommendations in the World Federation of Societies of Biological Psychiatry guideline for depressive episodes, and based on a more differentiated data set, LTG was rated as Category of Evidence "B" (limited positive evidence from controlled studies) or Recommendation Grade "3" (based on Category of Evidence "B"); this was not changed in the 2010 update. ${ }^{14}$ In the recently published S3 guidelines on the diagnosis and therapy of BDs, Pfennig et a ${ }^{17}$ ranked LTG in the acute treatment and prevention of BD as " 0 ," with the recommendation defined as "open." The authors criticized studies by Calabrese et $\mathrm{al}^{21}$ and Geddes et $\mathrm{al}^{22}$ for not meeting primary endpoints, or for only showing slight effects in pooled data. They argued that downgrading LTG in the use of acute depressive episode results from trials and reviews that showed more modest results. . $^{5,18,22,23,39}$ Mok et $\mathrm{al}^{16}$ also referred to the publications by Calabrese et $\mathrm{al}^{21}$ and van der Loos et $\mathrm{al}^{32}$ and advised that LTG be used as an add-on treatment for patients already on lithium, but not as monotherapy in bipolar depression; this received a Recommendation Grade "A." One reason that these studies showed only slightly positive effects could be due to the need for slow titration over 5 to 6 weeks for a daily dosage of $200 \mathrm{mg} /$ day. Here the first antidepressant effects occur. ${ }^{30}$ Because most trials last only up to 8 weeks, possible antidepressant effects can be diminished. Another reason for the modest effects could also be found in high PLC response rates, so small antidepressant effects of LTG were not represented adequately. ${ }^{40}$ For the treatment of mania, neither in acute states nor in prophylaxis was an antimanic effect confirmed; ${ }^{19,20,29}$ therefore, LTG is not recommended in any guideline for the treatment of mania in BD., 10,12,15-17

In the long-term treatment of bipolar depression, LTG plays a more convincing role. Results have consistently shown that LTG extends the time to relapse for depression, not only in a head-to-head comparison with PLC, but also with well-established comparators like lithium. ${ }^{29,32,36}$ In the World Federation of Societies of Biological Psychiatry guidelines, LTG is ranked as recommendation grade "A."13 The Canadian guidelines ${ }^{9}$ and the British guidelines ${ }^{8}$ also recommend LTG in maintenance treatment (Table 3). As promoted in the NICE guidelines, ${ }^{10}$ LTG does show positive effects as an add-on therapy. ${ }^{33,34}$ Mok et al ${ }^{16}$ even state in their 2011 guideline that LTG should only be used for maintenance treatment when effects occurred previously in acute use (Recommendation Grade "A"). ${ }^{37,40}$ One advantage of long-term treatment is the good tolerability of LTG. Severe side effects were reported only in a small number of patients. Mostly mild side effects occurred and included headache, nausea, or dizziness. ${ }^{5,6,41}$ No metabolic side effects or weight gain were reported during LTG therapy, and no evidence of inducing shifts into mania was found.,42 
We did not perform a systematic search of articles dealing with the use of LTG in BD because we wanted to discuss the role and position of LTG in recent therapy guidelines on $\mathrm{BD}$, and to recapitulate its changing position throughout time based on newer publications used in the development of treatment guidelines. Results of our study emphasize the changing position of LTG in international therapy guidelines. Therefore, the findings of our review article may stimulate a meta-analysis of all studies, including unpublished data.

\section{Conclusion}

LTG, as a maintenance therapy and as an add-on drug, is a well-tolerated option, even in therapy-refractory patients; however, further studies are required.

\section{Disclosure}

The authors report no conflicts of interests in this work.

\section{References}

1. Merikangas KR, Jin R, He JP, et al. Prevalence and correlates of bipolar spectrum disorder in the world mental health survey initiative. Arch Gen Psychiatry. 2011;68(3):241-251.

2. Fitton A, Goa KL. Lamotrigine. An update of its pharmacology and therapeutic use in epilepsy. Drugs. 1995;50(4):691-713.

3. Li X, Ketter TA, Frye MA. Synaptic, intracellular, and neuroprotective mechanisms of anticonvulsants: are they relevant for the treatment and course of bipolar disorders? J Affect Disord. 2002;69(1-3) $1-14$.

4. Prica C, Hascoet M, Bourin M. Antidepressant-like effect of lamotrigine is reversed by veratrine: a possible role of sodium channels in bipolar depression. Behav Brain Res. 2008;191(1):49-54.

5. Goldsmith DR, Wagstaff AJ, Ibbotson T, Perry CM. Lamotrigine: a review of its use in bipolar disorder. Drugs. 2003;63(19):2029-2050.

6. Seo HJ, Chiesa A, Lee SJ, et al. Safety and tolerability of lamotrigine: results from 12 placebo-controlled clinical trials and clinical implications. Clin Neuropharmacol. 2011;34(1):39-47.

7. Lamictal ${ }^{\circledR}$ (lamotrigine) tablets, chewable dispersible tablets, orally disintegrating tablets [prescribing information]. North Carolina: GlaxoSmithKline; Dec 2011; Revised 09/2012. Available from: http://us.gsk.com/products/assets/us_lamictal.pdf. Accessed November 24, 2012.

8. Goodwin GM; for Consensus Group of the British Association for Psychopharmacology. Evidence-based guidelines for treating bipolar disorder: revised second edition - recommendations from the British Association for Psychopharmacology. J Psychopharmacol. 2009;23(4):346-388

9. Yatham LN, Kennedy SH, Schaffer A, et al. Canadian Network for Mood and Anxiety Treatments (CANMAT) and International Society for Bipolar Disorders (ISBD) collaborative update of CANMAT guidelines for the management of patients with bipolar disorder: update 2009 Bipolar Disord. 2009;11(3):225-255.

10. National Institute for Health and Clinical Excellence. Bipolar Disorder: The Management of Bipolar Disorder in Adults, Children and Adolescents, in Primary and Secondary Care. NICE Clinical Guideline 38. London: National Institute for Health and Clinical Excellence; 2006 [updated March 30, 2010]. Available from: http:// www.nice.org.uk/nicemedia/live/10990/30193/30193.pdf. Accessed September 10, 2012.
11. Grunze H, Kasper S, Goodwin G, et al; World Federation of Biological Psychiatry Task Force on Treatment Guidelines for Bipolar Disorders. World Federation of Societies of Biological Psychiatry (WFSBP) guidelines for biological treatment of bipolar disorders. Part I: Treatment of bipolar depression. World J Biol Psychiatry. 2002;3(3):115-124.

12. Grunze H, Kasper S, Goodwin G, et al; WFSBP Task force on Treatment Guidelines for Bipolar Disorders. The World Federation of Societies of Biological Psychiatry (WFSBP) Guidelines for Biological Treatment of Bipolar Disorders, Part II: Treatment of Mania. World J Biol Psychiatry. 2003;4(1):5-13.

13. Grunze H, Kasper S, Goodwin G, Bowden C, Möller HJ; WFSBP Task Force on Treatment Guidelines for Bipolar Disorders. The World Federation of Societies of Biological Psychiatry (WFSBP) guidelines for the biological treatment of bipolar disorders, part III: maintenance treatment. World J Biol Psychiatry. 2004;5(3):120-135.

14. Grunze H, Vieta E, Goodwin GM, et al; WFSBP Task Force On Treatment Guidelines for Bipolar Disorders. The World Federation of Societies of Biological Psychiatry (WFSBP) Guidelines for the Biological Treatment of Bipolar Disorders: Update 2010 on the treatment of acute bipolar depression. World J Biol Psychiatry. 2010;11(2):81-109.

15. Grunze H, Vieta E, Goodwin GM, et al. The World Federation of Societies of Biological Psychiatry (WFSBP) guidelines for the biological treatment of bipolar disorders: update 2009 on the treatment of acute mania. World J Biol Psychiatry. 2009;10(2):85-116.

16. Mok YM, Chan HN, Chee KS, et al; Ministry of Health. Ministry of Health clinical practice guidelines: bipolar disorder. Singapore Med J. 2011;52(12):914-918; quiz 919.

17. Pfennig A, Bschor T, Baghai T, et al. S3 guidelines on diagnostics and therapy of bipolar disorders: development process and essential recommendations. Nervenarzt. 2012;83(5):568-586. German.

18. Amann B, Born C, Crespo JM, Pomarol-Clotet E, McKenna P. Lamotrigine: when and where does it act in affective disorders? A systematic review. J Psychopharmacol. 2011;25(10):1289-1294.

19. Cipriani A, Barbui C, Salanti G, et al. Comparative efficacy and acceptability of antimanic drugs in acute mania: a multiple-treatments meta-analysis. Lancet. 2011;378(9799):1306-1315.

20. Yildiz A, Vieta E, Leucht S, Baldessarini RJ. Efficacy of antimanic treatments: meta-analysis of randomized, controlled trials. Neuropsychopharmacology. 2011;36(2):375-389.

21. Calabrese JR, Bowden CL, Sachs GS, Ascher JA, Monaghan E, Rudd GD. A double-blind placebo-controlled study of lamotrigine monotherapy in outpatients with bipolar I depression. Lamictal 602 Study Group. J Clin Psychiatry. 1999;60(2):79-88.

22. Geddes JR, Calabrese JR, Goodwin GM. Lamotrigine for treatment of bipolar depression: independent meta-analysis and meta-regression of individual patient data from five randomized trials. Br J Psychiatry. 2009;194(1):4-9.

23. Calabrese JR, Huffman RF, White RL, et al. Lamotrigine in the acute treatment of bipolar depression: results of five double-blind, placebocontrolled clinical trials. Bipolar Disord. 2008;10(2):323-333.

24. Frye MA, Ketter TA, Kimbrell TA, et al. A placebo-controlled study of lamotrigine and gabapentin monotherapy in refractory mood disorders. J Clin Psychopharmacol. 2000;20(6):607-614.

25. Brown EB, McElroy SL, Keck PE Jr, et al. A 7-week, randomized, double-blind trial of olanzapine/fluoxetine combination versus lamotrigine in the treatment of bipolar I depression. J Clin Psychiatry. 2006;67(7):1025-1033.

26. Brown E, Dunner DL, McElroy SL, et al. Olanzapine/fluoxetine combination vs lamotrigine in the 6-months treatment of bipolar I depression. Int J Neuropsychopharmacol. 2009;12(6):773-782.

27. Schaffer A, Zuker P, Levitt A. Randomized, double-blind pilot trial comparing lamotrigine versus citalopram for the treatment of bipolar depression. J Affect Disord. 2006;96(1-2):95-99.

28. Nolen WA, Kupka RW, Hellemann G, et al. Tranylcypromine vs lamotrigine in the treatment of refractory bipolar depression: a failed but clinically useful study. Acta Psychiatr Scand. 2007;115(5): $360-365$. 
29. Bowden CL, Calabrese JR, Sachs G, et al; Lamictal 606 Study Group. A placebo-controlled 18-month trial of lamotrigine and lithium maintenance treatment in recently manic or hypomanic patients with bipolar I disorder. Arch Gen Psychiatry. 2003;60(4):392-400.

30. Calabrese JR, Bowden CL, Sachs G, et al; Lamictal 605 Study Group. A placebo-controlled 18-month trial of lamotrigine and lithium maintenance treatment in recently depressed patients with bipolar I disorder. J Clin Psychiatry. 2003;64(9):1013-1024.

31. Goodwin GM, Bowden CL, Calabrese JR, et al. A pooled analysis of 2 placebo-controlled 18-month trials of lamotrigine and lithium maintenance in bipolar I disorder. J Clin Psychiatry. 2004;65(3): $432-441$.

32. van der Loos ML, Mulder PG, Hartong EG, et al. Efficacy and safety of lamotrigine as add-on treatment to lithium in bipolar depression: a multicenter, double-blind, placebo-controlled trial. J Clin Psychiatry. 2009;70(2):223-231.

33. van der Loos ML, Mulder P, Hartong EG, et al; for LamLit Study Group. Long-term outcome of bipolar depressed patients receiving lamotrigine as add-on to lithium with the possibility of the addition of paroxetine in nonresponders: a randomized, placebo-controlled trial with a novel design. Bipolar Disord. 2011;13(1):111-117.

34. Chang JS, Moon E, Cha B, Ha K. Adjunctive lamotrigine therapy for patients with bipolar II depression partially responsive to mood stabilizers. Prog Neuropsychopharmacol Biol Psychiatry. 2010;34(7): $1322-1326$

35. Nierenberg AA, Ostacher MJ, Calabrese JR, et al. Treatment-resistant bipolar depression: a STEP-BD equipoise randomized effectiveness trial of antidepressant augmentation with lamotrigine, inositol, or risperidone. Am J Psychiatry. 2006;163(2):210-216.

36. Ichim L, Berk M, Brook S. Lamotrigine compared with lithium in mania: a double-blind randomized controlled trial. Ann Clin Psychiatry. 2000;12(1):5-10.

37. Calabrese JR, Suppes T, Bowden CL, et al. A double-blind, placebocontrolled, prophylaxis study of lamotrigine in rapid-cycling bipolar disorder. J Clin Psychiatry. 2000;61(11):841-850.

38. Bowden CL, Calabrese JR, McElroy SL, et al. The efficacy of lamotrigine in rapid cycling and non-rapid cycling patients with bipolar disorder. Biol Psychiatry. 1999;45(8):953-958.

39. Swartz HA, Thase ME. Pharmacotherapy for the treatment of acute bipolar II depression: current evidence. J Clin Psychiatry. 2011;72(3): 356-366.

40. Vieta E, Carné X. The use of placebo in clinical trials on bipolar disorder: a new approach for an old debate. Psychother Psychosom. 2005;74(1):10-16.

41. Ketter TA, Greist JH, Graham JA, Roberts JN, Thompson TR, Nanry KP. The effect of dermatologic precautions on the incidence of rash with addition of lamotrigine in the treatment of bipolar I disorder: a randomized trial. J Clin Psychiatry. 2006;67(3):400-406.

42. Goldberg JF, Calabrese JF, Saville BR, et al. Mood stabilization and destabilization during acute and continuation phase treatment for bipolar I disorder with lamotrigine or placebo. J Clin Psychiatry. 2009;79(9):1273-1280.

43. Licht RW, Nielsen JN, Gram LF, Vestergaard P, Bendz H. Lamotrigine versus lithium as maintenance treatment in bipolar I disorder: an open, randomized effectiveness study mimicking clinical practice. The 6 th trial of the Danish University Antidepressant Group (DUAG-6). Bipolar Disord. 2010;12(5):483-493.

44. Smith LA, Cornelius V, Warnock A, Tacchi MJ, Taylor D. Pharmacological interventions for acute bipolar mania: a systematic review of randomized placebo-controlled trials. Bipolar Disord. 2007;9(6):551-560.

45. Fatemi SH, Rapport DJ, Calabrese JR, Thuras P. Lamotrigine in rapidcycling bipolar disorder. J Clin Psychiatry. 1997;58(12):522-527.
46. Hurley SC. Lamotrigine update and its use in mood disorders. Ann Pharmacother. 2002;36(5):860-873.

47. Kusumakar V, Yatham LN. Lamotrigine treatment of rapid cycling bipolar disorder. Am J Psychiatry. 1997;154(8):1171-1172.

48. Walden J, Hesslinger B, van Calker D, Berger M. Addition of lamotrigine to valproate may enhance efficacy in the treatment of bipolar affective disorder. Pharmacopsychiatry. 1996;29(5):193-195.

49. Walden J, Schaerer L, Schloesser S, Grunze H. An open longitudinal study of patients with bipolar rapid cycling treated with lithium or lamotrigine for mood stabilization. Bipolar Disord. 2000;2(4):336-339.

50. Walden J, Grunze H. Prospective, randomized study on valproate, lithium, valproate + lithium and lamotrigine in Bipolar I rapid cycling patients. Proceedings of the SMRI Research Center conference; November 8, 2002; Bethesda, MD.

51. Maina G, Albert U, Rosso G, Bogetto F. Olanzapine or lamotrigine addition to lithium in remitted bipolar disorder patients with anxiety disorder comorbidity: a randomized, single-blind, pilot study. J Clin Psychiatry. 2008;69(4):609-616.

52. Sharma V, Khan M, Corpse C. Role of lamotrigine in the management of treatment-resistant bipolar II depression: a chart review. J Affect Disord. 2008;111(1):100-105.

53. Suppes T, Marangell LB, Bernstein IH, et al. A single blind comparison of lithium and lamotrigine for the treatment of bipolar II depression. J Affect Disord. 2008;111(2-3):334-343.

54. Bowden CL, Calabrese JR, Ketter TA, Sachs GS, White RL, Thompson TR. Impact of lamotrigine and lithium on weight in obese and nonobese patients with bipolar I disorder. Am J Psychiatry. 2006;163(7): 1199-1201.

55. Dossett EC, Land AJ, Gitlin MJ, Frye MA. Lack of mania prophylaxis associated with lamotrigine monotherapy in manic-predominant bipolar I disorder. J Clin Psychiatry. 2007;68(6):973-974.

56. Ghaemi SN, Schrauwen E, Klugman J, et al. Long-term lamotrigine plus lithium for bipolar disorder: One year outcome. J Psychiatr Pract. 2006;12(5):300-305.

57. Mokhber N, Lane CJ, Azarpazhooh MR, et al. Anticonvulsant treatments of dysphoric mania: a trial of gabapentin, lamotrigine and carbamazepine in Iran. Neuropsychiatr Dis Treat. 2008;4(1):227-234.

58. Nierenberg AA. Combined olanzapine plus fluoxetine modestly improves symptoms of acute bipolar I depression compared to lamotrigine. Evid Based Ment Health. 2007;10(1):12.

59. Rubio G, López-Muñoz F, Alamo C. Effects of lamotrigine in patients with bipolar disorder and alcohol dependence. Bipolar Disord. 2006;8(3):289-293.

60. Schieber FC, Boulton DW, Balch AH, et al. A non-randomized study to investigate the effects of the atypical antipsychotic aripiprazole on the steady-state pharmacokinetics of lamotrigine in patients with bipolar I disorder. Hum Psychopharmacol. 2009;24(2):145-152.

61. Spaulding T, Westlund R, Thomason C, White R, Dann R, Thompson T. Adjunctive treatment for mood stabilization of patients with bipolar I disorder treated with lamotrigine. CNS Spectr. 2006;11(9):711-716; quiz 719 .

62. Calabrese JR, Rapport DJ, Youngstrom EA, Jackson K, Bilai S, Findling RL. New data on the use of lithium, divalproate, and lamotrigine in rapid cycling bipolar disorder. Eur Psychiatry. 2005;20(2):92-95.

63. Jadad AR, Moore RA, Carroll D, et al. Assessing the quality of reports of randomized clinical trials: is blinding necessary? Control Clin Trials. 1996;17(1):1-12.

64. Calabrese JR, Bowden CL, McElroy SL, et al. Spectrum of activity of lamotrigine in treatment-refractory bipolar disorder. Am J Psychiatry. 1999;156(7):1019-1023.

65. Obrocea GV, Dunn RM, Frye MA, et al. Clinical predictors of response to lamotrigine and gabapentin monotherapy in refractory affective disorders. Biol Psychiatry. 2002;51(3):253-260. 
Neuropsychiatric Disease and Treatment

Dovepress

\section{Publish your work in this journal}

Neuropsychiatric Disease and Treatment is an international, peerreviewed journal of clinical therapeutics and pharmacology focusing on concise rapid reporting of clinical or pre-clinical studies on a range of neuropsychiatric and neurological disorders. This journa is indexed on PubMed Central, the 'PsycINFO' database and CAS.

The manuscript management system is completely online and includes a very quick and fair peer-review system, which is all easy to use. Visit http://www.dovepress.com/testimonials.php to read real quotes from published authors.

Submit your manuscript here: http://www.dovepress.com/neuropsychiatric-disease-and-treatment-journal 